\title{
Artificial Intelligence Engineering for Cyborg Technology Implementation
}

\author{
Sadique Shaikh* \\ Institute of Management \& Science (IMS), India
}

Submission: April 01, 2018; Published: May 17, 2018

*Corresponding author: Sadique Shaikh Md, Institute of Management \& Science (IMS), M.S, India, Email: sids_nsk@rediffmail.com

Keywords: Artificial intelligence; Cyborg technology; Neuron command operating devices; Cyborg intelligence; Brain computer interfaces; Cyborg analysis design; Bionic organs; Medical robotics domains; Human biology

Abbreviations: CAD: Cyborg Analysis Design; BCI: Brain Computer Interfaces; NCOD: Neuron Command Operating Devices; CI: Cyborg Intelligence

\section{Introduction}

As humans live longer there is a growing need for availability of organs for transplant however shortage in donations necessitates the development of artificial alternatives with AI often called "Bionic". Advances in medicine have led to the availability of artificial blood, replacement joints, heart valves, and heart-lung machines that are common implanted using AI for Bionic organs. One of the primary and utilitarian goals of artificial intelligence research is to develop machines with human-like intelligence. Great progress has been made since the start of AI as a field of study. One dominating research paradigm in AI has been based on the assumption that various aspects of human intelligence can be described and understood well enough to the extent that it can be simulated by computer programs through smart representational frameworks and generic reasoning mechanisms. Now a day's fusion take place Biological beings and computer systems share some common physical foundations. Communication in both biological nervous systems and computer systems, for example, depends on electrical signals. Yet, the gap between these two classes of vastly different systems is obvious and bridge with "Cyborg Intelligence".

Since researchers and practitioners confused between Bionic/AI and Cyborg, let me clear in last attempt to it. As I discussed already Bionic is biological functions, methods, systems and procedures mimic electronically with neuron interfacing but Cyborg is another possibility in Medical Robotics domains. Cyborg "Cybernetic organism" is a being with both organic and Biomechatronic body parts using which human can increase their power in all means and branch of study is "Cyborgology".

\section{Modeling}

\section{Cyborg analysis design (CAD) model}

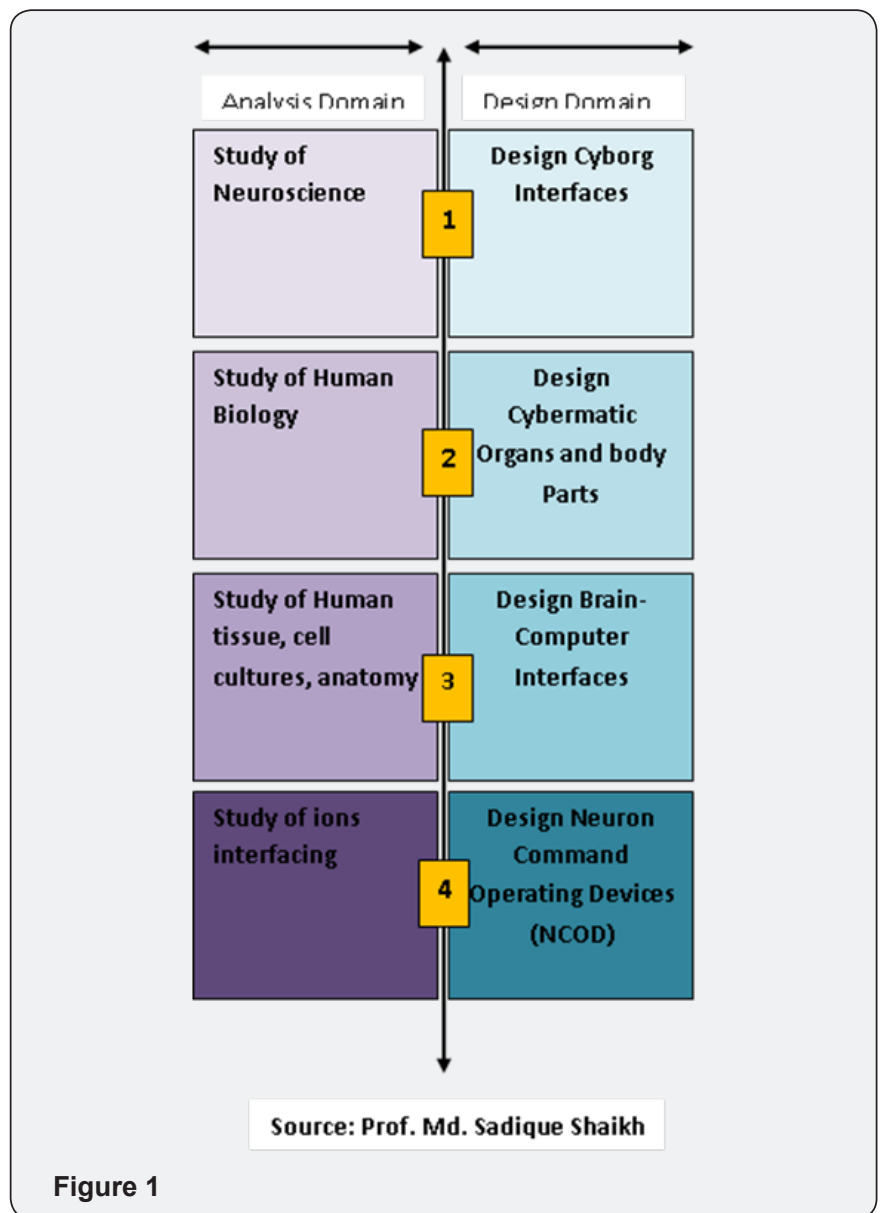


This is first model and with the help of this display I want to clarify the fundamental analysis and designing issues for Cyborg engineering. This model based on four tiers 1 to 4 with further split each stage Analysis domain and Design domain. At first stage detail studies need to carry of Neuroscience theory to analyzed Cyborg with intention what you want to engineer and in design domain design Cyborg interfaces accordingly. At the stage two researchers have to study very first human biology and anatomy and functions of biological organs to interface and synch with Cybermatic parts and at design domain devices engineer and fabricated accordingly. At stage three studies of bio-membranes, tissues, cells and anatomy have to make to design "Brain Computer Interfaces (BCI)" with ions-electrons commands and signals exchange to establish communication between biological and electronic system. In last stage bio-potential and how to interface ions with electronic devices need to carry to engineer "Neuron Command Operating Devices (NCOD)" /Cybermatic devices (Figure 1) [1].

\section{Cyborg interface support model}

In continuation of first model this is second exhibit "Cyborg Interface and Support" engineering model to implement Cyborg Intelligence. It is based on four criterions with further division into two domains (Figure 2) [2,3].

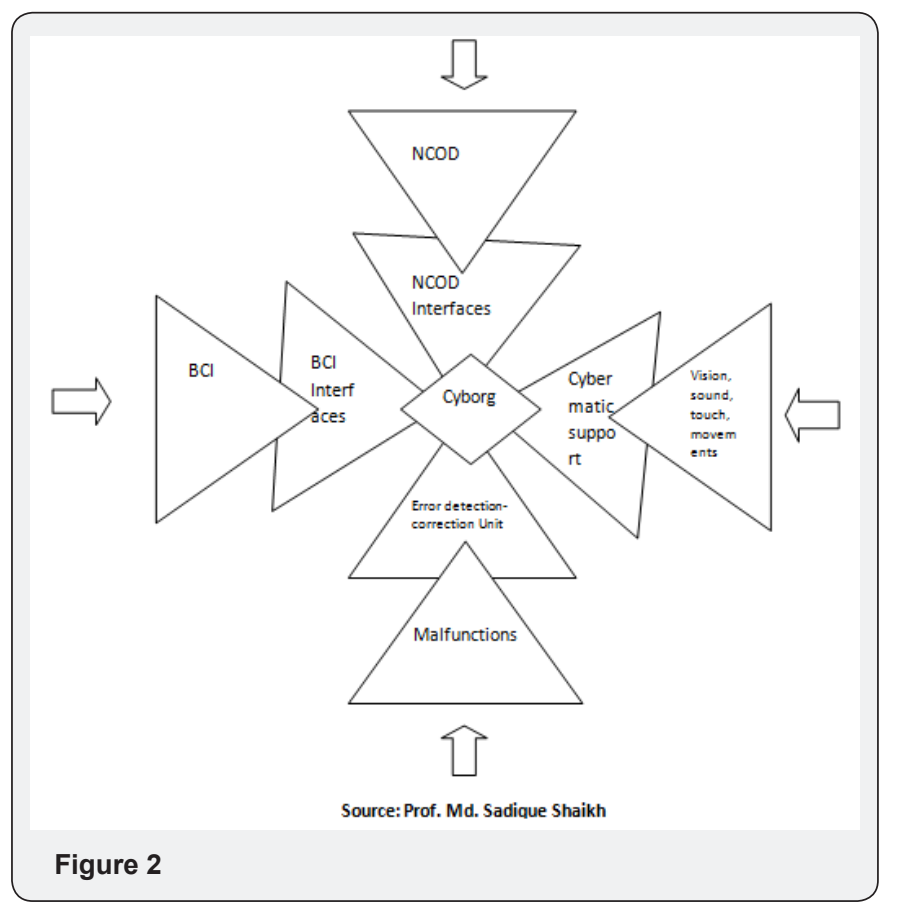

Instead of sequential it is random model but covered four most important designing issues to implement Cyborg Intelligence (CI). We need to design strong Brain Computer Interface with depth BCI engineering and how to synch biological system with electronic system in short precise system engineering need. Another aspect is How to design Neuron Command Operating Devices (NCOD) and how to interface NCOD with biological system. Next important thing is how to analyze and design Vision, Sound, touch and Movements with NCOD for Cybermatic support engineering. The last important engineering issue which we can not neglect, since Cybermatic devices 24 hours functional with human body lot of chances of malfunction due to continuous processing hence "Error detection and correction" engineering is important for continuous accurate error free working $[4,5]$.

\section{Conclusion}

With the help of this short communication I tried to understand what engineering parameters and steps are important and where have to change from routine AI engineering for Cyborg technology implementation with discussing two models Cyborg Analysis Designing model and Cyborg Interfaces Support model lucidly.

\section{Acknowledgment}

I really thankful to my wife Safeena Shaikh for her moral support my son Md. Nameer Shaikh for his love which keeps me fresh with new ideas and my close friend Tanvir Sayyed for her positive support with me and my motivator Dr. B.N. Gupta for his constant support.

\section{References}

1. NSF/EC Understanding on Co-operation in Information TechnologiesStrategic Research Workshops IST-1999-12077.

2. Sadique Shaikh Md (2013) Analysis and modeling of Strong A.I to engineer BIONIC brain for humanoid robotics application. In American Journal of Embedded System and Applications, Published by Science Publishing Group, New York, USA, 1(2).

3. Sadique Shaikh Md (2017) Ultra Artificial Intelligence (UAI): Redefing AI fir New Research Dimension. In Advanced Robotics \& Automation (ARA), OMICS International, London, ISSN No: 2168-9695, Vol. 6(2): $1-3$.

4. Sadique Shaikh Md (2017) Fundamental Engineering for BrainComputer Interfacing (BCI): Initiative for Neuron-Command Operating Devices. In Computational Biology and Bioinformatics (CBB), Science PG, USA, 5(4): 50-56.

5. Sadique Shaikh Md (2018) Defining ultra artificial intelligence (UAI) implementation using bionic (biological-like-electronics) brain engineering insight. MOJ App Bio Biomech 2(2): 127-128. 
Your next submission with Juniper Publishers will reach you the below assets

- Quality Editorial service

- Swift Peer Review

- Reprints availability

- E-prints Service

- Manuscript Podcast for convenient understanding

- Global attainment for your research

- Manuscript accessibility in different formats ( Pdf, E-pub, Full Text, Audio)

- Unceasing customer service

Track the below URL for one-step submission https://juniperpublishers.com/online-submission.php 